\title{
Lightweight Design to Improve Crushing Behaviour of Multi-stitched Composite Tubular Structures under Impact Loading
}

\author{
A. Rabiee and H. Ghasemnejad ${ }^{1}$ \\ Centre for Structures, Assembly and Intelligent Automation, \\ Cranfield University, MK43 0AL, UK
}

\begin{abstract}
This paper presents experimental and numerical studies on the effect of multi-stitching pattern on the energy absorption capability of composite tubular structures under impact loading. A new multi-stitching pattern was developed to study the increase of specific energy absorption capabilities in GFRP and CFRP crash absorbers. The stitching pattern on both specimens showed a significant increase in energy absorption capability under impact loading. According to our results, the specific energy absorption of GFRP and CFRP composite tubes are $17 \%$ and $18 \%$ higher than non-stitched specimens respectively. A multi-shell finite element model was constructed to predict the axial crushing behaviour and energy absorption capability of composite structures under impact loading. The method is based on an energy-based contact card modelling technique in the stitched and non-stitched area, and the initiation of main central crack growth occurs when the critical separation (PARAM function) is attained, and this represents the functionality of the stitched area during an impact event. The developed numerical approach is efficient in terms of accuracy and simplicity in comparison with the existing methods for multi-layered composites structures.
\end{abstract}

Keywords: Crashworthiness; Composites; Multi-stitching; Impact; LS-DYNA

\footnotetext{
${ }^{1}$ Corresponding Author: e-mail: hessam.ghasemnejad@cranfield.ac.uk (Hessam Ghasemnejad), Tel: +44 (0) 1234754395. 


\section{Introduction}

The global interest in the aerospace and automotive industry is oriented towards lightweight structures for optimum energy efficiency without compromising occupant safety. The major design parameter is aligned with passenger safety; therefore, materials with high energy absorption capabilities are developed for light-weighting-safety trade-off. Composite materials have a great energy absorption capability in terms of crashworthiness and significantly reduce structural weight in aerospace and automotive applications [1-2]. Crashworthiness is the ability of a vehicle to protect its passengers or occupants from injuries or deaths in case of sudden impact, and also related to the energy absorption capability by controlled failure modes. However, in any case, protection is up to a certain severity of the impact.

Composite absorbers align well with crashworthiness characteristics with outstanding performance compared to metallic structures [3-4]. Composite absorbers provide progressive crushing behaviour and are rapidly increasing due to higher energy absorption capacity per unit weight in comparison with metals; this means higher Specific Energy Absorption (SEA) levels that surpass achievable levels in metals [5-6]. The effective response of energy absorption of thin-walled composite tubular absorbers depends on the design of its sub-structure; and their stability is determined by lay-up, geometry, laminate design, and strain rate sensitivity and their progressive failure mechanism. The main factor affecting progress crushing of tubular structures is interlaminar and intralaminar fracture toughness [7].

Various methods have been introduced to increase energy absorption capabilities by improving interlaminar toughness such as stitching through the thickness which results into the improvement of energy absorption capabilities of composites without increasing the weight of the structure [8-10].

In stitching through the thickness, the fibre-thread induces heterogeneity in the $2 \mathrm{D}$ mesoscale of the structure. The structural integrity of the composite absorber which has been stitched through the thickness depends on the stitching pattern [11]. This through the thickness reinforcement has shown enormous improvement in Mode-I delamination resistance whilst stabilising Mode-II crack growth using continuous fibres [10, 12-13]. Cauchi-Savona et al. [14] investigated the influence of stitching through the thickness on fracture toughness using carbon and glass NCFs laminates under impact loading and noted that selecting an optimised stitched configuration causes 30\% improvement in the energy absorption. A similar conclusion was obtained by Soloimurugan and velmurugan $[15,16]$, that studied composite cylindrical 
shells with various stacking sequence, fibre orientation and stitching on the progressive crushing of glass/polyester under axial compression. It has been noted that stitching improves energy absorption capabilities. The authors also noted that the allocation of axial fibres in outer surface results into stable crushing due to development of more petals, whereas axial fibres allocated in the inner surface caused higher energy absorption. Circumferential delamination improves energy absorption capabilities. Korkiakoski et al. [17] performed an experimental study on the stitched non-crimp fabric (NFC) GFRP box structure and concluded that stitching affects damage progression and fatigue life. Ghasemnejad et. al. [18,19] experimentally investigated effects of stitching through the thickness on delamination failure of composite box structures with a hybrid combination of unidirectional CFRP and GFRP composite box structures with a laminate design of $\left[\mathrm{C}_{90} / \mathrm{G}_{0}\right]_{7}$ under quasi-static loading. The author concluded that the stitching through the thickness significantly improves energy absorption capability and showed the highest energy absorption compared with the non-stitched specimen. Mode-I delamination test with the same lay-up was carried out to investigate the influence of stitching on delamination crack growth and energy absorption of composite absorbers. The significant increase in interlaminar fracture toughness and energy absorption capabilities in the thin-walled structures was obtained from utilising stitching through the thickness. More recently, Rabiee and Ghasemnejad [20] investigated the influence of single and multi-stitching through the thickness which led to pattern stitching on energy absorption capabilities of GFRP cylindrical shells under $2 \mathrm{~mm} / \mathrm{sec}$ quasi-static loading. The authors showed that the stitched locations and stitching pattern significantly influence the behaviour of progressive crushing. They also noted that as stitched locations are close to each other, the crushing behaviour becomes more progressive with increased energy absorption capability, which indicates a desirable crashworthy behaviour.

A more detailed knowledge of the material behaviour is indispensable to implement a reliable numerical simulation. Various finite element modelling has been developed with different approaches to meet the demand for accuracy and reliability of the results. One strategy is SOFT parameter implemented in LS-DYNA software to map pre-damaged and consequently create a progressive crash front of a CFRP square tube [21]. Another strategy is an implementation of solid and shell elements to idealise a force-displacement graph [22]. This method is used for modelling of crack propagation with finite cohesion elements [23] that consists of a shell element representing the material and a solid element to represent delamination failure. Alternatively, material 54 of LS-DYNA material library is used to predict crushing behaviour 
and idealised force-displacement graph [24]. The simulation is found to be in good agreement with experimental results. In another study [18] it was concluded that Enhanced Composite Damage Model of LS-DYNA material library, which is material models 54 and 55, for GFRP box structures was found to be in accordance to experimental results when it was modelled as double shell configuration. Similar evaluations were obtained by other researchers that using multi-shell configuration can predict energy absorption and maximum force under crushing [25-26]. Many studies focused on the contact parameter [27], crack propagation modelling with de-cohesion elements [28] or user-defined material model which requires extensive experimental investigations [29].

In all previous researches, several parameters were investigated to increase fracture toughness in composite thin-walled absorbers. The effects of single and multi-stitched locations and patterns have been previously demonstrated and showed significant influence on energy absorption capabilities by increasing inter/intra-laminar fracture toughness under quasi-static loading. However, in real life applications, standard impact test should be carried in order to investigate the material behaviour under impact loading. For this reason, it was necessary to investigate the effect of multi-stitching on pre-preg GFRP and CFRP under impact loading to establish its effect on the SEA. Moreover, several FE modelling was introduced with unique techniques to achieve ideal force/displacement curves focusing on different parameters including contact definition and crack propagation modelling. In this paper, a crushing finite element model is developed that can be used in stitched composite sections under axial impact loading using a multi-shell configuration using LS-DYNA software. This paper experimentally and numerically aims to study impact response of multi-stitched composite structures to improve specific energy absorption capabilities. The stitch pattern used for all stitched specimens (see Figure 1).

\section{Experimental Method}

\subsection{Material and Specimens}

Two different materials were selected to study stitching pattern under impact loading. In previous studies pre-preg GFRP was used to carry out an extensive research on the location of stitching and energy absorption. Based on the authors' previous experimental investigation on the influence of single, multi and pattern stitching using GFRP composite section under quasistatic loading [20], it was shown that stitching pattern of 10-15-20-25-30-35 mm (see Figure 1) from top of the crash absorbers can significantly improve the specific energy absorption capability with $15 \%$ increase using Kevlar fibre yarn. 
In this study, CFRP and GFRP pre-preg composite materials were chosen to study the effect of stitching pattern on the impact behaviour of composite tubes. All dimensions are illustrated in Figure 2.

Composite sections were fabricated from glass/epoxy $\left(\rho=2250 \mathrm{~kg} / \mathrm{m}^{3}\right)$ with a laminate design of $[-45 / 45 / 0 / 90 / 0 / 90]_{\mathrm{S}}$ to create a symmetric twelve-ply quasi-isotropic laminate and carbon/epoxy $\left(\rho=1750 \mathrm{~kg} / \mathrm{m}^{3}\right)$ with a laminate design of $[-45 / 45 /-45 / 45 / 0 / 90 / 0 / 90 / 0 / 90 / 0]_{\mathrm{S}}$ using hand lay-up techniques. Both material properties are shown in Table 1. The through the thickness reinforcement took place by needle insertion $(1.1 \mathrm{~mm}$ in diameter) perforating the uncured composite laminate along the circumference of the tube in a zigzag format. The stitching was approximately $6 \mathrm{~mm}$ apart using Kevlar yarn fibres (1.1 $\mathrm{mm}$ in diameter).

Tan et. al. [31] experimentally and numerically investigated the effect of fibre yarns on stitched laminates and concluded that Kevlar and Carbon stitched laminates of similar thread thickness have similar improvement in interlaminar fracture toughness.

Each line of stitching was marked and carefully followed to cover the circumference of the composite tube. Four to six specimens were tested in each case of study to find the mean deviation of the experimental results. The progressive crushing in all specimens was initiated with $45^{\circ}$ bevelled trigger mechanism. All stitched specimens were subjected to multi-stitched locations as shown in Figure 1.

Force-displacement curve was the main concentration of this research to carry out a comparison of the energy absorption capability of each case. In this research, apart from introducing multistitching to the stitched specimens, all other parameters such as geometry, lay-up, strain rate, curing and loading which affect energy absorption capabilities were kept constant. Since the input kinetic energy is constant for all specimens, the displacement is the key factor. Reduced displacement shows higher energy absorption capability of the stitched composite crash absorbers if subjected to the same crashing displacement as non-stitched specimens. 


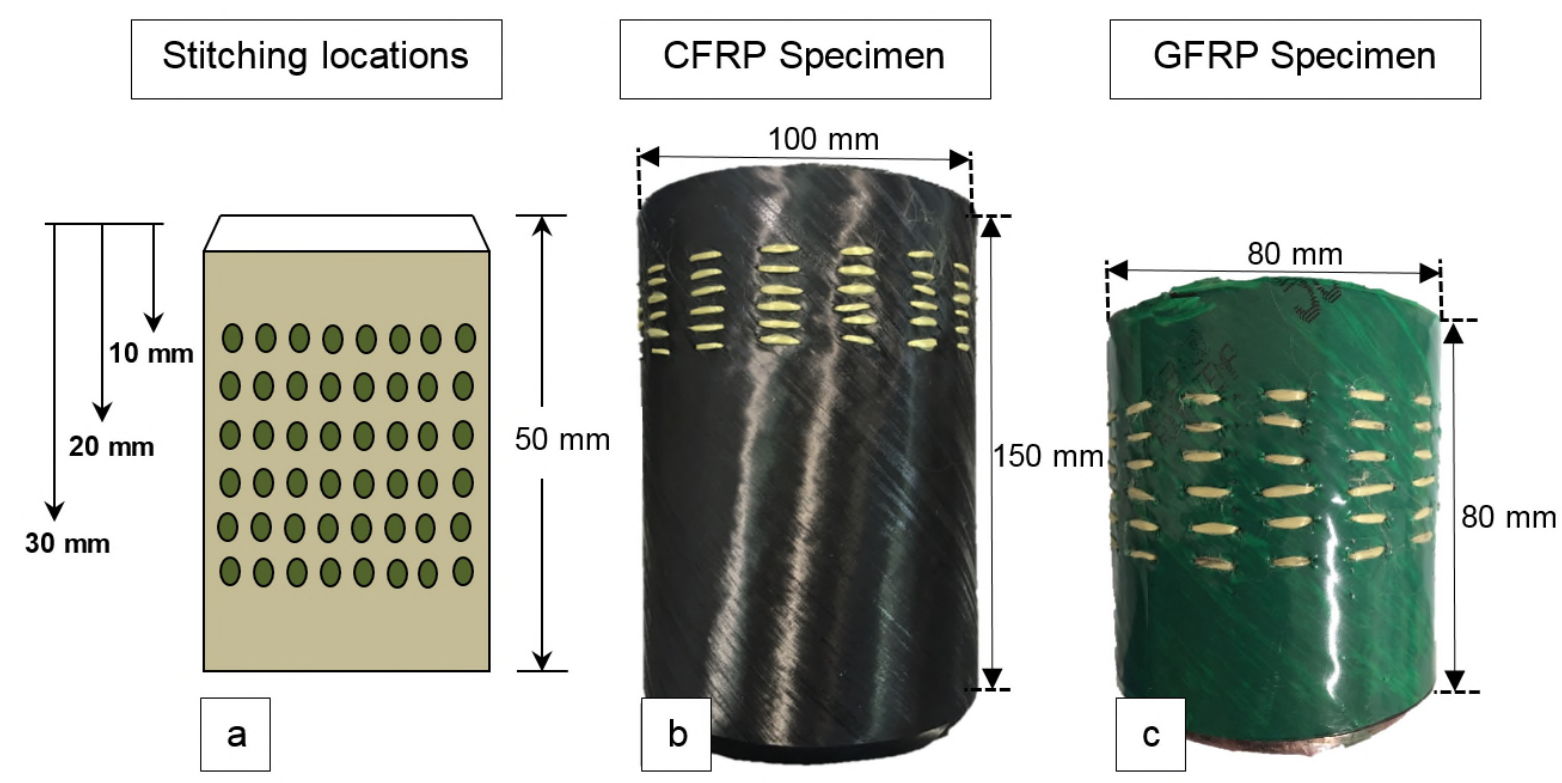

Figure 1. a) Multi-stitched locations at 10-15-20-25-30-35 mm b) uncured CFRP multi-stitched specimen c) uncured GFRP multi-stitched specimen

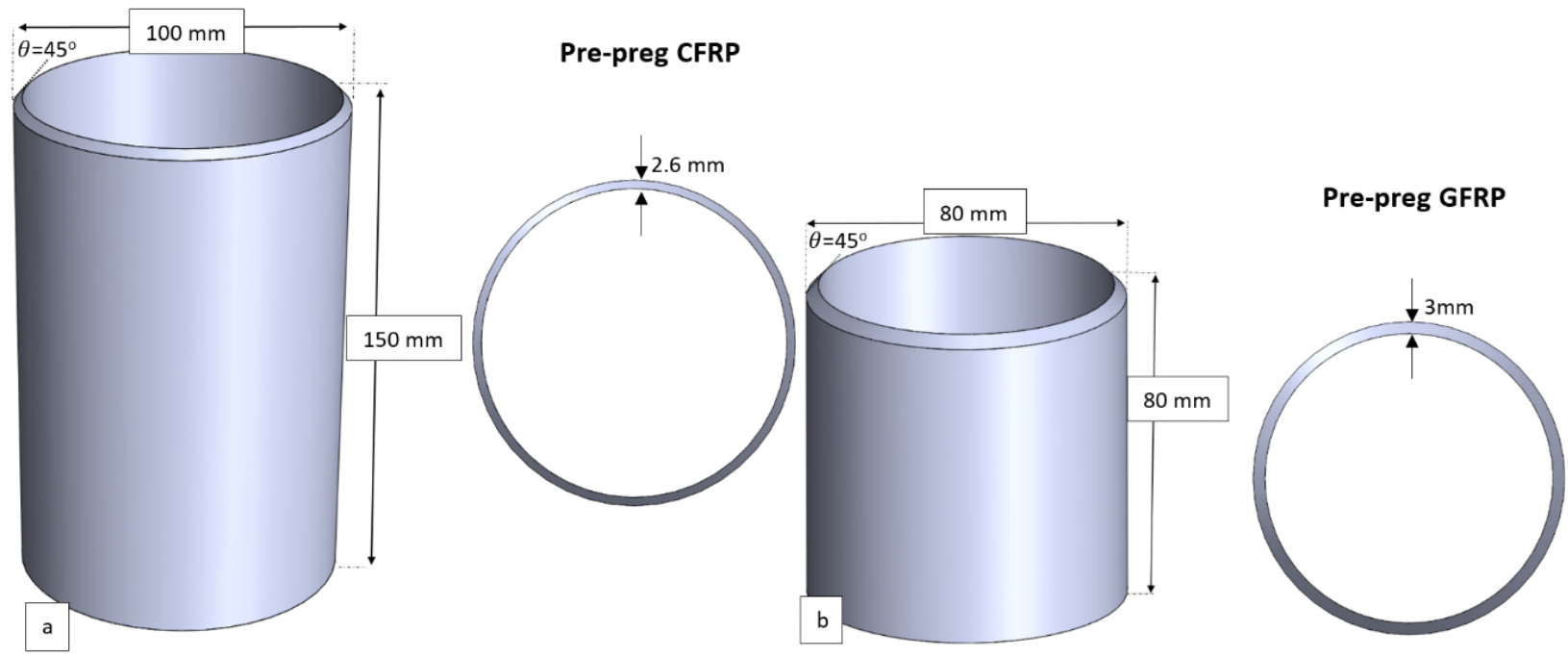

Fig 2. Composite absorbers for a) CFRP and b) GFRP geometry configurations. 


\begin{tabular}{|c|c|c|c|c|c|c|c|}
\hline \multicolumn{8}{|c|}{ GFRP (TenCate E772) } \\
\hline $\begin{array}{c}E_{1} \\
(\mathbf{G P a})\end{array}$ & $\begin{array}{c}E_{2} \\
(\mathrm{GPa})\end{array}$ & $\begin{array}{c}G_{12} \\
(\mathrm{GPa})\end{array}$ & $v_{12}$ & $\begin{array}{c}\sigma_{u} 0^{\circ} \\
(\mathrm{MPa})\end{array}$ & $\begin{array}{l}\sigma_{u} 90^{\circ} \\
(\mathrm{MPa})\end{array}$ & $\begin{array}{c}\tau_{s} \\
(\mathrm{MPa})\end{array}$ & $\begin{array}{l}V_{f} \\
(\%)\end{array}$ \\
\hline $39 \pm 3$ & $11.8 \pm 1$ & $3.2 \pm 0.5$ & 0.29 & $836 \pm 20$ & $29 \pm 2$ & $97 \pm 4$ & 58 \\
\hline \multicolumn{8}{|c|}{ CFRP (Hexcel T300/914C) } \\
\hline $\begin{array}{c}E_{1} \\
(\mathbf{G P a})\end{array}$ & $\begin{array}{c}E_{2} \\
(\mathrm{GPa})\end{array}$ & $\begin{array}{c}G_{12} \\
(\mathrm{GPa})\end{array}$ & $v_{12}$ & $\begin{array}{c}\sigma_{u} 0^{o} \\
(\mathrm{MPa})\end{array}$ & $\begin{array}{l}\sigma_{u} 90^{\circ} \\
(\mathrm{MPa})\end{array}$ & $\begin{array}{c}\tau_{s} \\
(\mathrm{MPa})\end{array}$ & $\begin{array}{l}V_{f} \\
(\%)\end{array}$ \\
\hline $67 \pm 5$ & $9.8 \pm 1$ & $4.8 \pm 1$ & 0.32 & $296 \pm 10$ & $27 \pm 3$ & $115.5 \pm 2$ & 42.5 \\
\hline
\end{tabular}

\subsection{Impact experimental setup}

Impact test was conducted by using a spring-loaded drop tower with impactor mass of 108.4 $\mathrm{kg}$ and drop height of $2.0 \mathrm{~m}$ with an initial velocity of $7.0 \mathrm{~m} / \mathrm{s}$ for all specimens. The configuration of spring and predetermined drop height enables to achieve higher velocity. In this case, the drop tower was set up for maximum output energy. The machine recorded a kinetic energy of 2672 Joules being applied to the specimens which are the maximum output energy of the drop tower. The hammerhead was released from a pre-determined height to initiate and record the load against time until it reaches the specimen and penetrates through the specimen, at this stage the impactor is decelerating and once the impact energy of $2672 \mathrm{~J}$ is absorbed by the specimen the impactor stops and the hammer then is pulled up by the machine. The tube leading edge impacted the dynamic load cell to record the force history during the event. An accelerometer was attached to the drop mass to record the data from the load cell and also it was sampled at $200,000 \mathrm{~Hz}$ by dynamic data acquisition system. Displacement is obtained through double integration of acceleration traces, and load cells gave the load values. A high-speed video camera with full HD resolutions (3,210 frames per second) was used to capture the crushing event.

\section{Results and Discussion}

Various stages of impact testing are shown in Figure 3. It was found that the failure mechanisms as shown in Figure 4a and 4b (CFRP) are brittle fracture mechanism which is a combination of fragmentations and transverse shearing mode with multiple short inter-laminar and longitudinal cracks. In Figure $4 c$ and $4 d$ representing GFRP tubes, the failure mechanisms are a combination of lamina bending and transverse shearing mode, which is a brittle fracture mode. Bundle fractures and lamina bending were observed with multiple short inter-laminar and longitudinal cracks. 


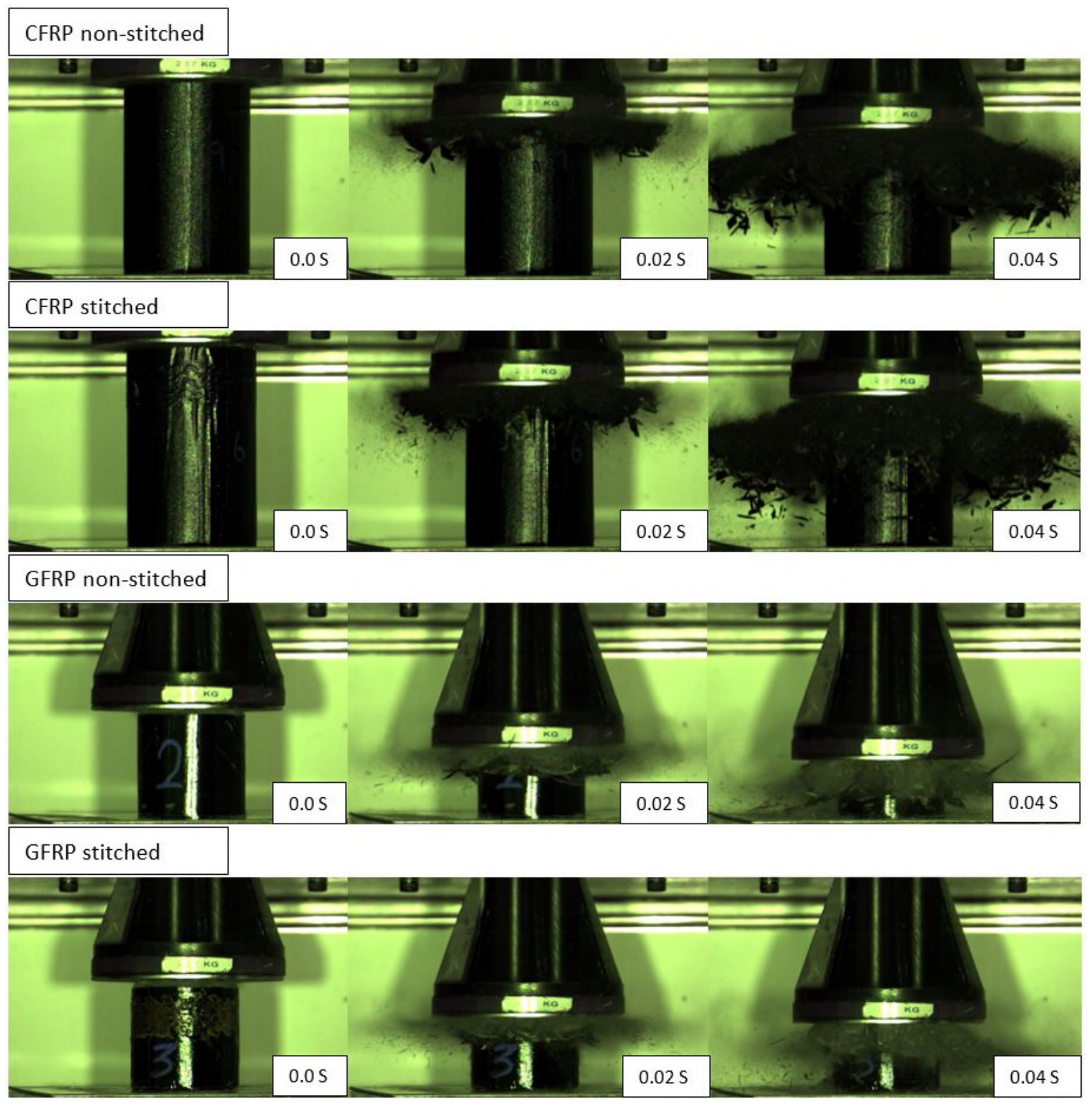

Fig 3. Various stages of impact testing at $0,0.2$ and 0.4 seconds, a) non-stitched CFRP b) Stitched CFRP c) nonstitched GFRP d) Stitched GFRP. 

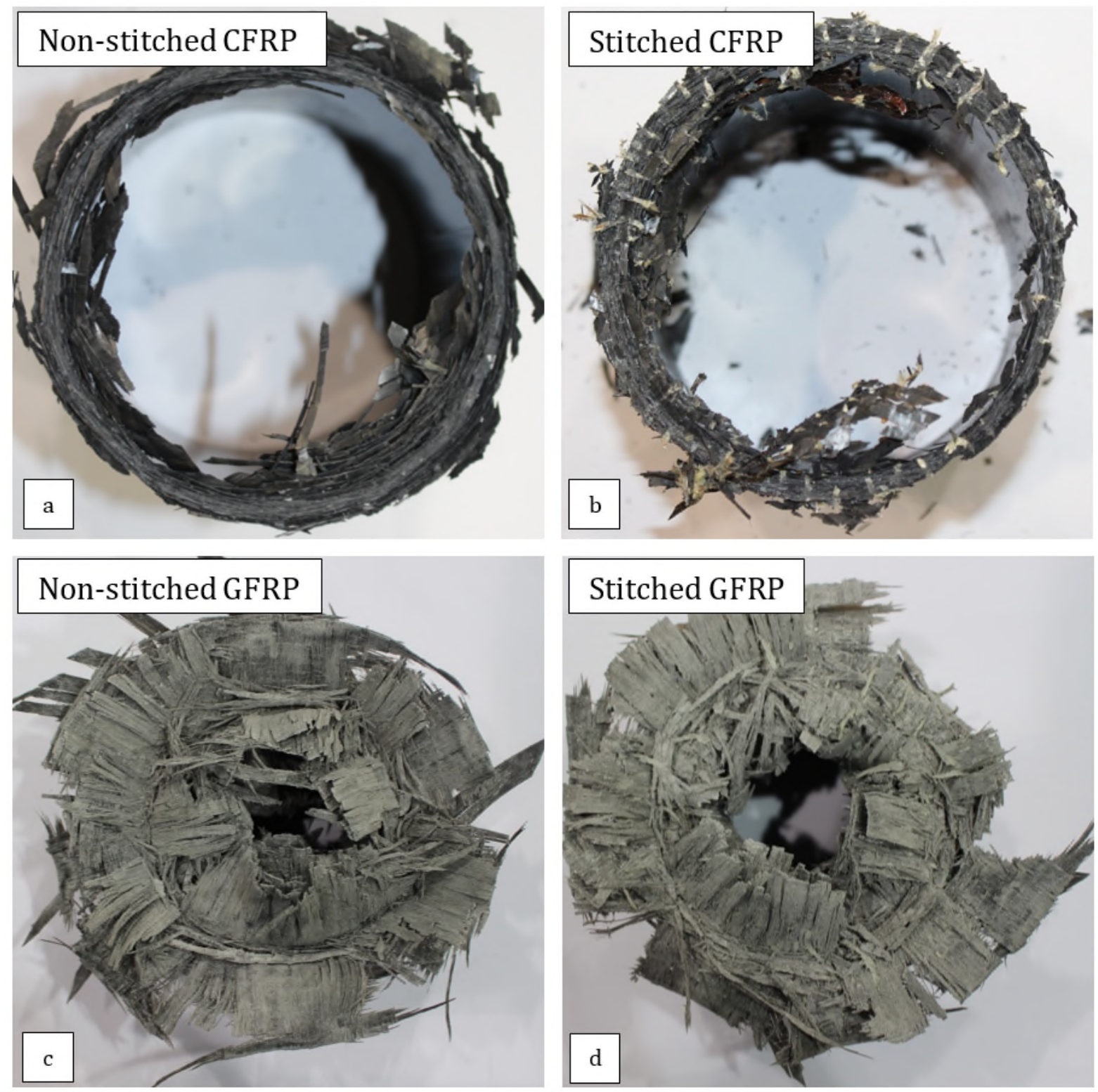

Fig 4. Impacted CFRP and GFRP plane morphology a) non-stitched CFRP b) stitched CFRP c) non-stitched GFRP d) stitched GFRP specimens.

Figures 5 and 6 compare the load-displacement curves of GFRP and CFRP stitched and nonstitched specimens under impact load respectively. The results clearly show a significant increase in energy absorption capability and crashworthiness behaviour indicated by a reduction of displacement, resulting from multi-stitching through the thickness. The specimens were all subjected to the same amount of kinetic energy, the stitched specimens were able to absorb the energy within shorter displacement, which increases specific energy absorption (SEA) value, which refers to the energy absorption per crushed mass of the specimen. 
Therefore, stitched specimens absorbed more energy than non-stitched ones under the condition of the same impact displacement.

Stitched GFRP absorbers performed outstandingly by reducing the crushing displacement by $8 \mathrm{~mm}$ ( $25 \%$ reduction of stroke penetration) and absorbed the same amount of energy as a nonstitched specimen, 2672 Joules. In crashworthiness design, an absorber must be able to absorb as much energy as possible to reduce the applied energy to the passengers. Stitched-GFRP specimen illustrates a crashworthy behaviour, as it was able to absorb the applied energy within a shorter stroke penetration compared with a non-stitched specimen. The aim of introducing stitching through the thickness was to increase fracture toughness and subsequently increasing of energy absorption capabilities and this has been achieved in both cases. Similarly, CFRP specimen subjected to stitching has shown significant improvement in energy absorption capability with $20 \%$ reduction of displacement.

The force-displacement diagrams do not start from zero as the sensors were off by 2 millimetres from the top of the specimen, from a predetermined setup. The gap between the striker and the tube is determined before the test and the margin was misread, hence the graphs, initiated after the crushing process took place, although the material stiffness and behaviour are unaffected.

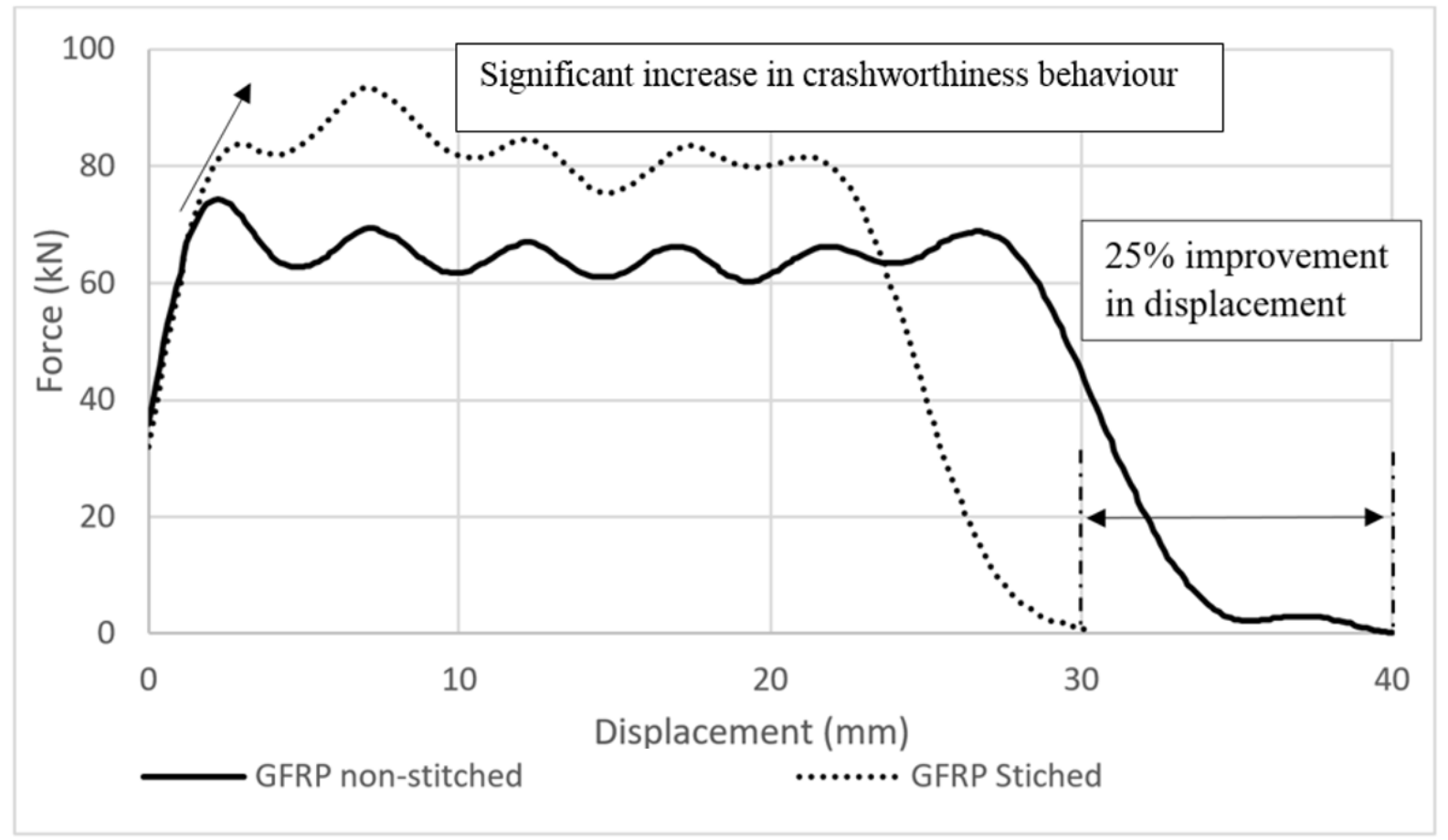

Fig 5. Force-displacement of GFRP stitched and non-stitched under impact loading. 


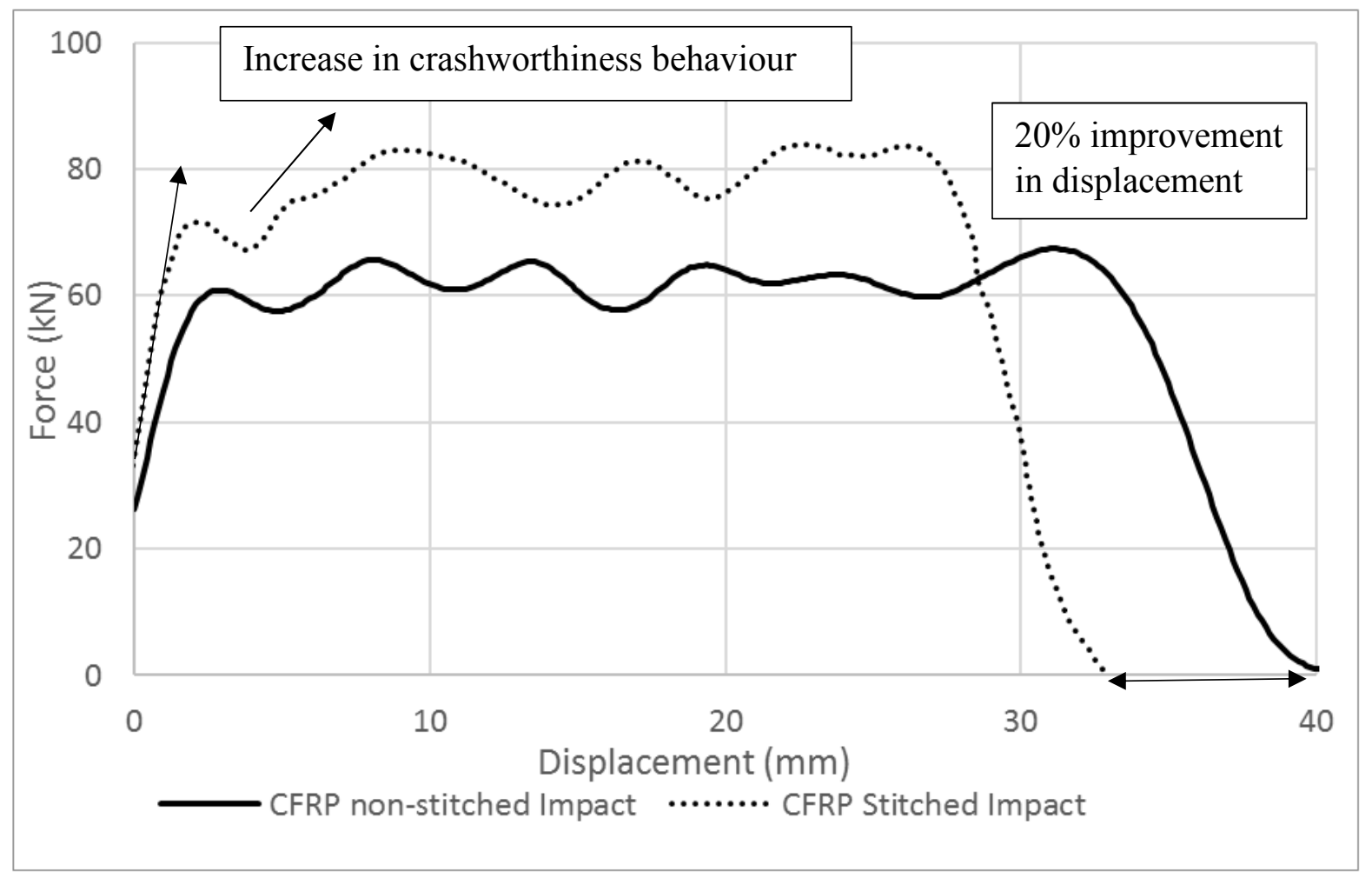

Fig 6. Force-displacement of CFRP stitched and non-stitched under impact loading.

Figure 7 represents the SEA values, which refers to the energy absorption per crushed mass of the specimen. The SEA value of the non-stitched GFRP was about $46 \mathrm{~kJ} / \mathrm{kg}$ and stitched GFRP was about $54.8 \mathrm{~kJ} / \mathrm{kg}$ under impact loading with $17 \%$ improvement. The SEA value of the nonstitched CFRP was about $52.5 \mathrm{~kJ} / \mathrm{kg}$ and the stitched CFRP was about $62.9 \mathrm{~kJ} / \mathrm{kg}$ under impact load with $18 \%$ improvement. It is concluded that stitching in all cases increases SEA value which indicates better crashworthiness behaviour.

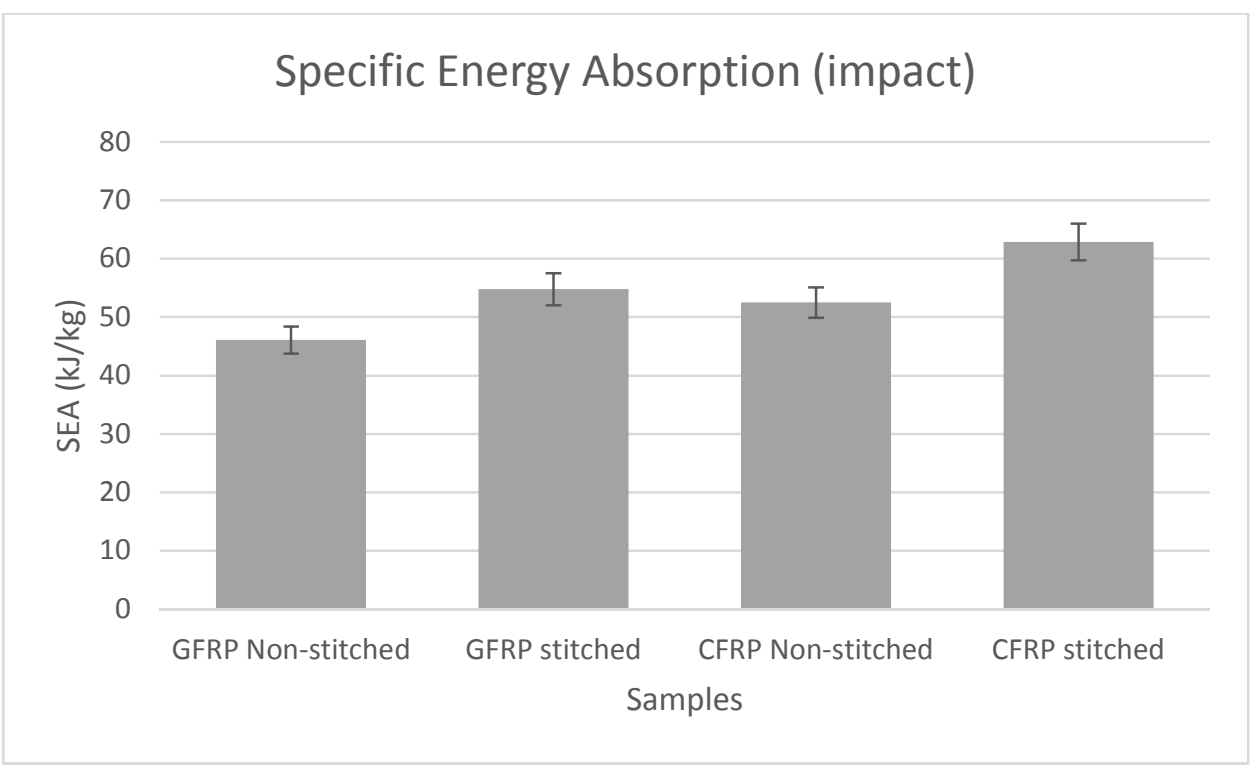

Fig 7. Specific energy absorption (SEA). 


\section{Numerical Simulation}

An explicit FE LS-DYNA code was used with multi-layered shell configuration to reduce numerical cost. Composite tubes were modelled as double layers of Belytschko-Tsay circular shell elements with one integration point in the element plane to represent the direction of the stacking sequence. The GFRP innermost shell has six through-thickness integration points with another six through-thickness integration points being assigned to the outermost shell to represent all twelve UD-layers. In the GFRP tube, each individual layer has a thickness of 0.25 $\mathrm{mm}$. The total thickness of both shells is $3 \mathrm{~mm}$. In CFRP the innermost shell has eleven through-thickness integration point with another eleven through-thickness integration points being assigned to the outermost shell to represent all 22 UD-layers with a thickness of each individual layer being $0.118 \mathrm{~mm}$. The total thickness of both shells is $2.6 \mathrm{~mm}$. Each fibre orientation was assigned with an insertion of an integration point in respect to the stacking sequence used with its associated thickness.

The outer radius of the GFRP tube was $40 \mathrm{~mm}$ with a thickness of $3 \mathrm{~mm}$. A double mid-plane shell model with a radius of $37.75 \mathrm{~mm}$ and $39.25 \mathrm{~mm}$ with a total length of $80 \mathrm{~mm}$ and 77.5 $\mathrm{mm}$ respectively were modelled as inner and outer shells of composite absorbers. Each shell was glued together so that the triggering at the top of the shell would not detach during the crushing process when a separate shell is used. In this triggering approach, two shells were used, one with $2.5 \mathrm{~mm}$ in height acting as the trigger (one element size), and the other depending on being inner or outer shell had its representative height assigned. Therefore, the top shell at each FEA case study represents the trigger (see Figure 8). Similarly, the CFRP tubes were modelled as double shells with radiuses of $48.05 \mathrm{~mm}$ and $49.35 \mathrm{~mm}$ representing the inner and outer shells with a length of $150 \mathrm{~mm}$ and $147.5 \mathrm{~mm}$ respectively.

Quadrilateral shell elements were used to mesh the surfaces of the double shells with an element size of $2.5 \mathrm{~mm} \times 2.5 \mathrm{~mm}$ [18-21]. The trigger mechanism was modelled by reducing the first-row thickness of the shell elements from $1.5 \mathrm{~mm}$ to $0.05 \mathrm{~mm}$ in each shell. A solid element rigid block was modelled to represent the striker. The LS-DYNA material model of enhanced_composite_damage (Mat_54-55), which is an orthotropic material with the failure criterion of Chang-Chang was used. This failure criterion is a modification of Hashin's failure criterion for assessing lamina failure with hourglass of 10\% [18-19].

Modelling interlaminar separation or delamination failure (Mode-I) requires either detailed experimental investigation for cohesive zone or three-dimensional representation that both 
result in an increase of computational and experimental costs. Delamination failure causes energy absorption and this can be modelled with multi-layered shell configuration with a contact card that is capable of $\mathrm{G}_{\mathrm{IC}}$ implemented energy release rate [24]. Defining One_Way_Surface_To_Surface_Tiebreak contact between the two shells can, therefore, predict the delamination resistance.

The tiebreak option enables the detachment of the contact surfaces after reaching a maximum normal stress (NFLS) or shear stress (SFLS). If the failure parameter, driven by occurring normal and shear stresses, become 1, the contact forces soften linearly until critical separation distance, PARAM is reached and the interface failure is completed. Based on the interlaminar utilisation of the contact, the parameters are determined by the mechanical properties of the matrix material. Consequently, shell layers detach when the interlaminar stress exceeds the matrix properties, which are mainly responsible for interlaminar strength. Maximum normal and shear stresses for the tiebreak contact are based upon the mechanical properties of the epoxy resin. The maximum contact distance (PARAM) is set to $0.15 \mathrm{~mm}$ and $0.32 \mathrm{~mm}$ for nonstitched and stitched specimen, calculated using Eqs. 4 and 5.

Automatic_Node_To_Surface contact was defined for the striker and inner shell with striker being master and inner shell being the slave. This prevents penetration of the crushing tube by its own nodes. All bottommost nodes of all shell element layers are constrained in their translational degrees of freedom. The coefficient of frictions between the composite material shells and the platen of the testing machine is set to 0.3 and 0.2 for static and dynamic respectively. The impactor is modelled as rigid with a mass of $108.4 \mathrm{~kg}$ and velocity of $7.0 \mathrm{~m} / \mathrm{s}$. All simulation results are smoothed using SAE $300 \mathrm{~Hz}$ filter [24]. 

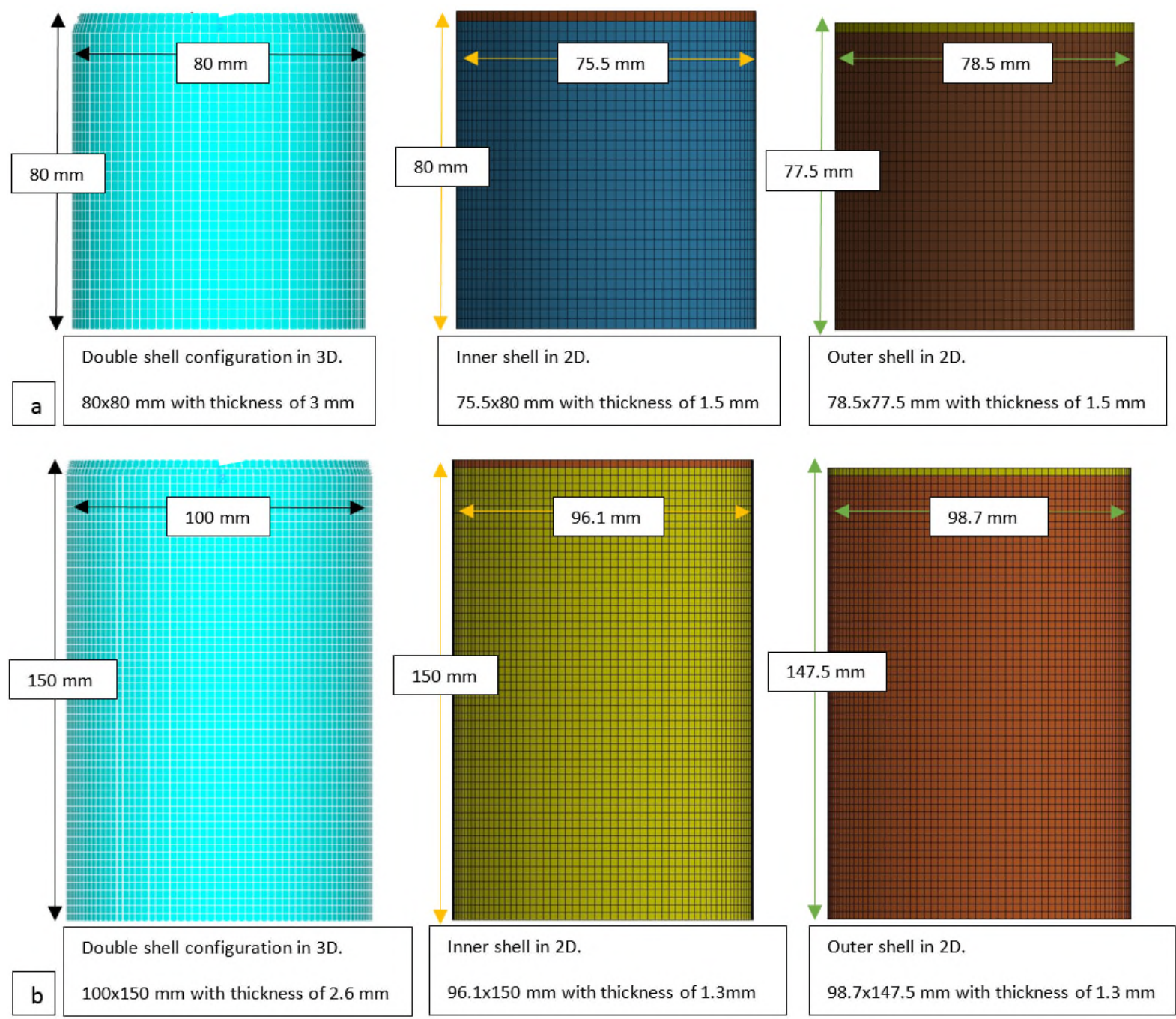

Figure 8 Shell geometry configuration. a) GFRP shell configuration b) CFRP shell configuration

The authors concluded that using double shell configuration reduces computational costs and accurately predicts energy absorption capability of the crash absorbers if the $\mathrm{G}_{\mathrm{IC}}$ and $\mathrm{G}_{\text {IIC }}$ energy release rates are scaled correctly to account for all the delaminated plies. However, the drawback is the crushed morphologies obtained from the model which is not a true representation of the experimental crushed morphologies.

\subsection{Delamination modelling}

One-way contact types allow for compression loads to be transferred between the slave nodes and the master segments. Tangential loads are also transmitted if relative sliding occurs when contact friction is active. A Coulomb friction formulation is used to transit from static to dynamic friction. This transition requires that the static friction coefficient is larger than the dynamic friction coefficient and a decay coefficient is defined. The one-way term in one-way contact is used to indicate that only the user-specified slave nodes are checked for penetration of the master segments. 
The algorithm ties nodes that are initially in contact by creating a linear spring and the debonding of the surface is initiated when the maximum stress criterion is met which leads to scaling down of the stress by a linear damage curve until the critical separation is reached and the spring is removed [32].

$$
\left(\frac{\sigma_{n}^{2}}{N F L S}\right)^{2}+\left(\frac{\sigma_{s}^{2}}{S F L S}\right)^{2}=1
$$

In which $\sigma_{n}$ and $\sigma_{s}$ are the normal and shear stresses acting at the interface, and NFLS, SFLS and PARAM function are the normal and shear strength of the tie and critical distance, respectively. Once the damage has initiated, the two surfaces begin to separate, and the interfacial stresses are then scaled down as a linear function of the separation distance. PARAM function which is the critical distance at which the failure occurs (i.e. deletion of tiebreak and advancing of delamination) [32].

$$
P A R A M=\frac{2 \times E_{t i e}}{S}
$$

where:

$$
S=\sqrt{\max \left(\sigma_{n}, 0\right)^{2}+\left(\sigma_{s}^{2}\right)^{2}}
$$

Due to the failure of the tiebreak interface, $E_{t i e}$ is the energy released. With trial and error procedures a sensitivity study was conducted of Mode-I and Mode-II to determine their relative effect(s) on the tiebreak failure process. It can be noted that for composite crushing simulations, Mode-I fracture is the dominant mode of failure during the tie-break failure process. Thus, a pure Mode-I delamination was assumed to simplify the simulations.

$$
G_{I C}=\frac{1}{2} \sigma_{n} P A R A M
$$

In this Eq. (4), the critical normal separation of the surface is determined, named as PARAM, based on the energy release rate in Mode-I $\left(G_{I C}\right)$ and the critical normal stress.

The effect of the number of plies on energy absorption capability was investigated to adopt tiebreak for each case of study and the tiebreak contact was defined only between these shell layers, rather than between individual plies. However, delamination could occur along any of the plies, if not all, as it was observed experimentally. The PARAM function was scaled by the ratio of the number of ply interfaces $n_{\text {delamination }}$ to the number of tiebreak interfaces $n_{\text {tie }}$ to account the energy dissipated as follow: 


$$
P A R A M^{\prime}=P A R A M \times \frac{n_{\text {delamination }}}{n_{\text {tie }}}
$$

Based on the experimental observations, it was assumed that delamination occurred among all plies. The values which were calculated in Eqs (4), and (5) are listed in Table 2 and Table 3.

Table 1 Tiebreak input parameters (non-stitched)

\begin{tabular}{|c|c|c|c|c|c|c|c|}
\hline $\begin{array}{c}E_{1} \\
(\mathrm{GPa})\end{array}$ & $\begin{array}{c}E_{2} \\
(\mathrm{GPa})\end{array}$ & $\begin{array}{c}G_{I C} \\
\left(\mathrm{~kJ} / \mathrm{m}^{2}\right)\end{array}$ & $\begin{array}{c}G_{I I C} \\
\left(\mathrm{~kJ} / \mathrm{m}^{2}\right)\end{array}$ & $\begin{array}{c}\text { NFLS } \\
(\mathrm{MPa})\end{array}$ & $\begin{array}{c}\text { SFLS } \\
(\mathrm{MPa})\end{array}$ & $\begin{array}{c}\text { PARAM } \\
(\mathrm{mm})\end{array}$ & $\begin{array}{c}\text { PARAM' } \\
(\mathrm{mm})(2 \mathrm{shells})\end{array}$ \\
\hline $39 \pm 3$ & $\begin{array}{c}11.8 \\
\pm 1\end{array}$ & 0.33 & 1.2 & 26.5 & 57.3 & 0.025 & 0.15 \\
\hline
\end{tabular}

Table 2 Tiebreak input parameters (stitched)

\begin{tabular}{|c|c|c|c|c|c|c|c|}
\hline $\begin{array}{c}E_{1} \\
(\mathrm{GPa})\end{array}$ & $\begin{array}{c}E_{2} \\
(\mathrm{GPa})\end{array}$ & $\begin{array}{c}G_{I C} \\
\left(\mathrm{~kJ} / \mathrm{m}^{2}\right)\end{array}$ & $\begin{array}{c}G_{I I C} \\
\left(\mathrm{~kJ} / \mathrm{m}^{2}\right)\end{array}$ & $\begin{array}{c}\text { NFLS } \\
(\mathrm{MPa})\end{array}$ & $\begin{array}{c}\text { SFLS } \\
(\mathrm{MPa})\end{array}$ & $\begin{array}{c}\text { PARAM } \\
(\mathrm{mm})\end{array}$ & $\begin{array}{c}\text { PARAM' } \\
(\mathrm{mm})(2 \text { shells })\end{array}$ \\
\hline $39 \pm 3$ & $\begin{array}{c}11.8 \\
\pm 1\end{array}$ & 0.69 & 1.2 & 26.5 & 57.3 & 0.052 & 0.32 \\
\hline
\end{tabular}

\subsection{Stitching modelling}

In simple non-stitched specimen, three different components were defined, inner shell, outer shell and the striker. The contact definition for inner shell and out shell was One_Way_Surface_To_Surface_Tiebreak option 8 with the static and dynamic coefficient of frictions of 0.3 and 0.2 respectively. It is worth mentioning that the stitching improves ModeI interlaminar fracture toughness, therefore the crack propagation resistance improves. An energy-based contact card was used to implicate this infinite element since contacts are defined for components in LS-DYNA explicit, five components were defined, inner shell, stitching of inner shell, outer shell, stitching of outer shell and the striker. The construction of either inner shell or outer shell consists of 14 shells, all these shells were glued together to perform as one shell. This enables defining different components on a shell. This method is used to define the trigger mechanism, defining two contact cards for the stitched models. Fourteen shells were used as mentioned, one for the trigger, 6 for the stitching, and 7 shells for the main body, this process was used for both inner and outer shells (see Figure 9) and the stitched area on both shells is aligned. The double contact definition technique consists of Tiebreak (option 8) contact with a static and dynamic coefficient of frictions of 0.3 and 0.2 respectively were assigned to inner and outer shells. In stitched delamination, the Mode-I crack propagation resistance increases, hence in the modelling of stitching, $G_{I C}$ is increased. Therefore, in nonstitched regions, the contact has the parameters mentioned in Table 2, and in stitched regions, the contact has the parameters mentioned in Table 3. The critical normal separation of the 
surface is considered in this contact card, known as PARAM function, based on the energy release rate in Mode-I $\left(G_{I C}\right)$ and the critical normal stress. In the stitched region, the Mode-I energy release rate for delamination growth increases according to table 3 , which is based on experimental studies and in the non-stitched region these parameters are set for normal ModeI energy release rate for delamination growth according to Table 2.

This method increases the Mode-I delamination crack growth resistance during the crushing process within the stitched area and consequently simulates the stitched area similar to experimental data (see Figure 10). The setup and the contact definitions were used in the nonstitched and stitched finite element model as shown in Figure 10.

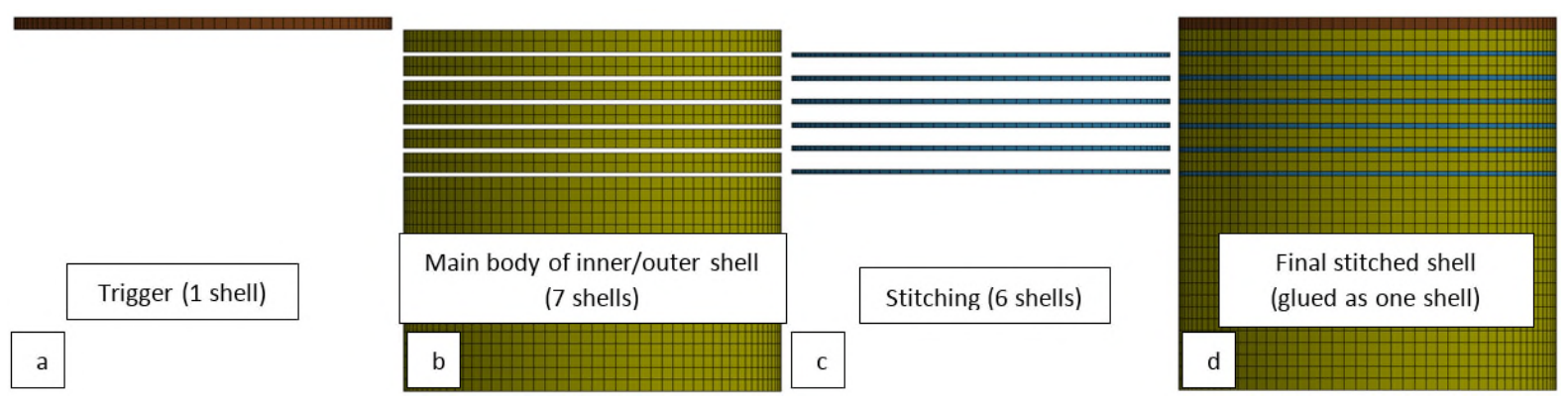

Figure 9. Construction of either inner or outer stitched shell. a) trigger mechanism (1 shell), b) main body of the inner/outer shell (7 shells), c) stitching (6 shells), d) final stitched shell, glued as one shell.

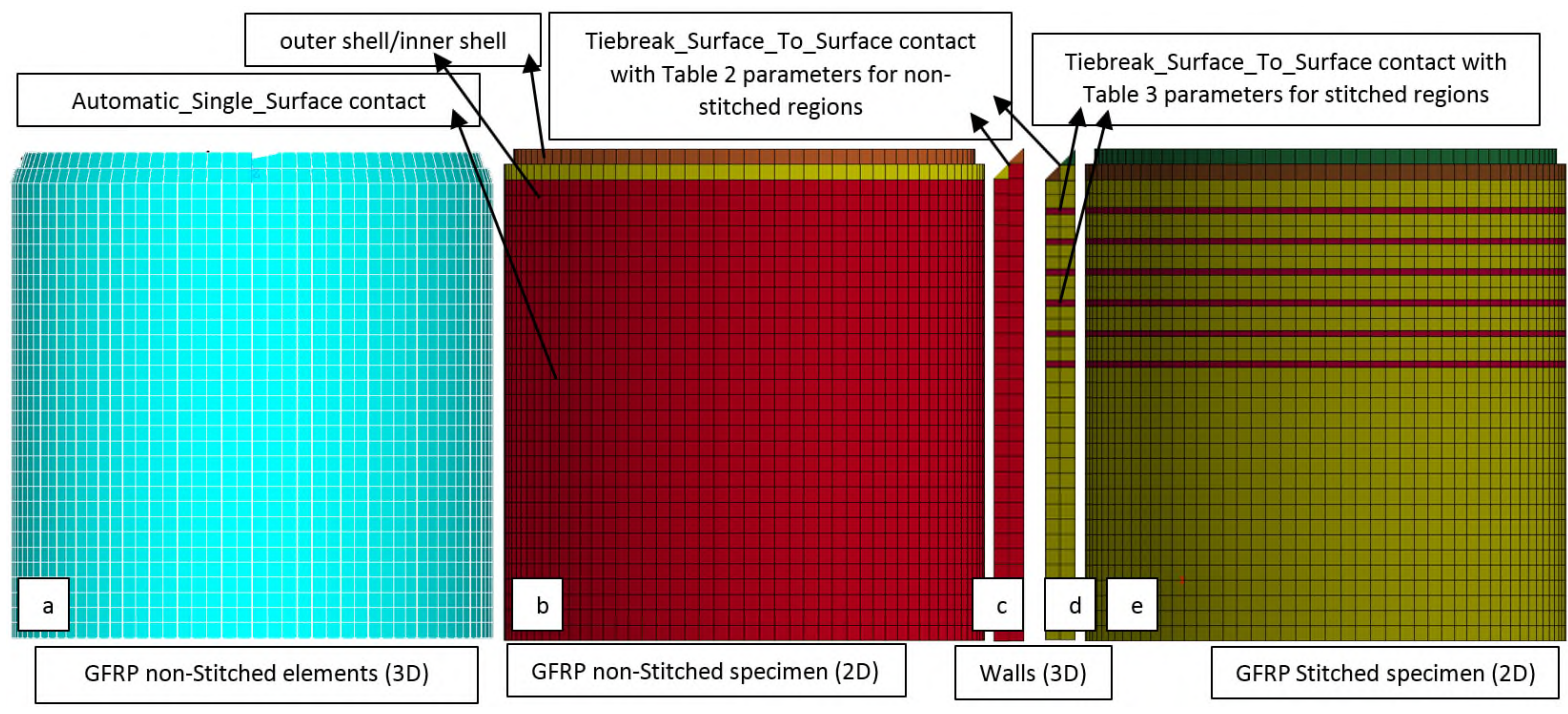

Figure 10. FEA contact definition of double shell stitched and non-stitched. a) GFRP non-stitched elements with thickness (3D), b) GFRP non-stitched without thickness (2D), c) GFRP non-stitched with thickness (3D), d) GFRP stitched with thickness (3D), GFRP stitched without thickness (2D)

Stitching was modelled using Tables 2 and 3 values with One_Way_Surface_To_Surface_Tiebreak contact card. This technique has led to capture both stitched and non-stitched crack growth behaviour through FEA. Figure 11, a) shows the results 
of stitched and non-stitched DCB tests for the mid-plane interface. The stitched specimen has increased Mode-I resistance and delayed crack initiation. Stitching through the thickness has increased crack propagation force by $40 \mathrm{~N}$. The FEA analysis results on the DCB tests of stitched and non-stitched specimens also clarified the effect of contact definition in increasing Mode-I delamination resistance, as shown in Figure 11.b. The combination of this effect on the stitched tubes (see Figure 9 and 10) can simulate the stitching effect.

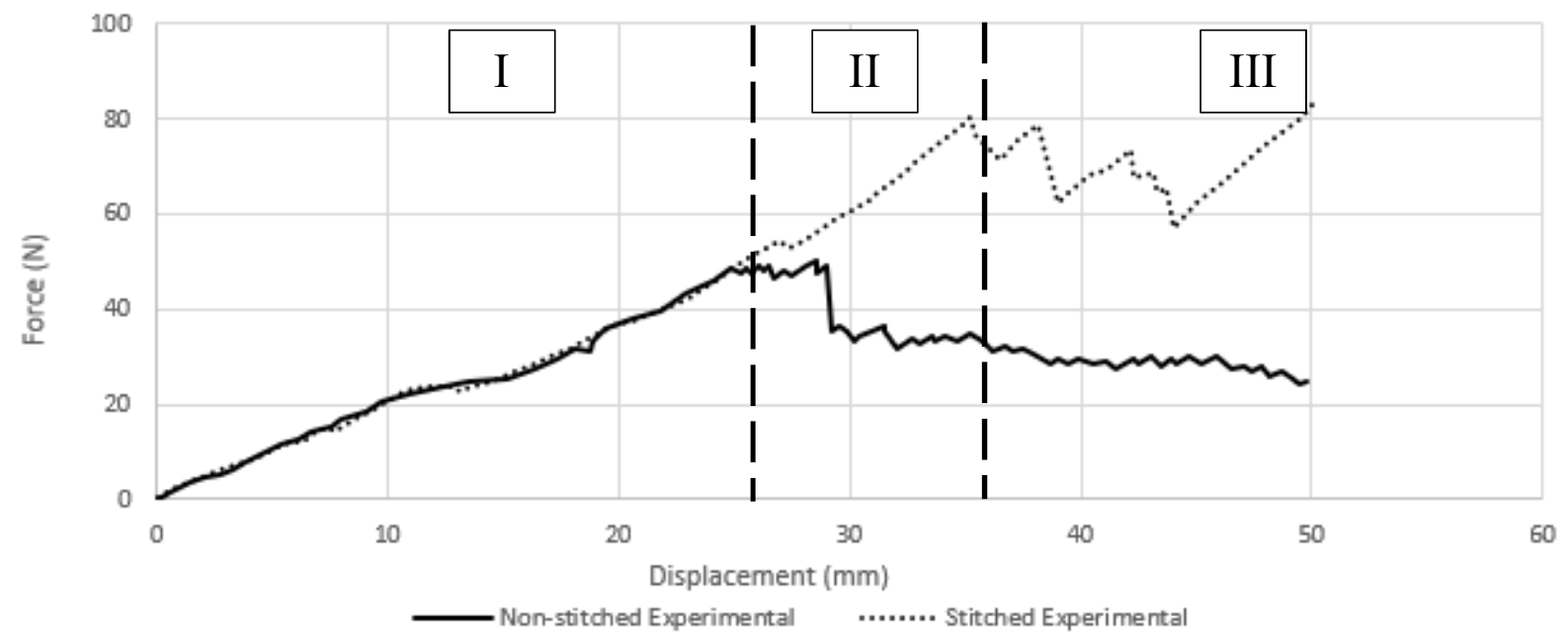

$\mathrm{I}=$ Elastic deformation, $\mathrm{II}=$ Crack initiation, $\mathrm{III}=$ Crack propagation

a

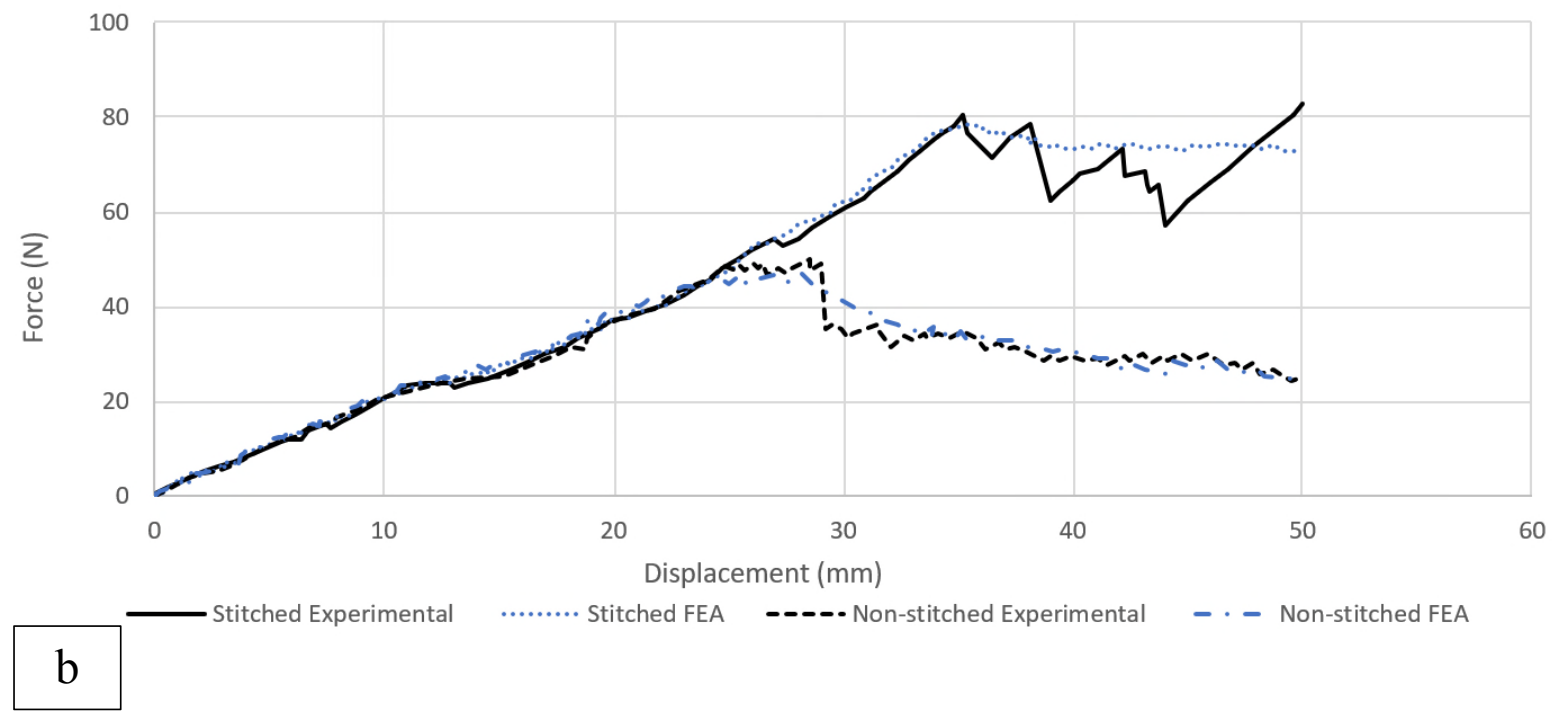

Figure 11. a) $I=$ elastic deformation, $\Pi I=$ crack initiation, $\Pi I I=$ crack propagation, comparison of stitched and nonstitched DCB tests for the mid-plane interface. b) FEA and experimental comparison of stitched and non-stitched $\mathrm{DCB}$ tests for mid-plane interface

In Figure 11, the cause of sharp random changes of the stitched experiment curves in Mode III is due to the location of the stitching, when the crack growth passes the first set of stitching, at 
$35 \mathrm{~mm}$, the load slightly drops, then it reaches the next set of stitching and the load rises and drops when reaching and passing the stitching locations, this behaviour continues until the last set of stitching are reached and a rapid increase in load is observed thereafter.

In summary, the delamination modelling approach was through Tiebreak option 8 , this contact card can define Mode-I and Mode-II energy release rate which enables capturing energy release rates. An energy-based approach was used to determine the input parameters for the tiebreak formulations to accurately simulate delamination between the plies. A scaling factor was introduced to account for ply interfaces that were not represented by a tiebreak definition. Using PARAM function to increase $\mathrm{G}_{\mathrm{IC}}$ energy release rate based on experimental studies.

CFRP and GFRP specimens were both modelled using the technique mentioned. Since contacts are defined for components in LS-DYNA explicit, 14 shells were used in total, 6 of which represent the stitching area. A total of 5 components were defined. Using multiple shells to represent the trigger, main body and 6 rows of stitching on each shell. The shell was then glued and meshed. This enables the shell to be recognised as one shell. The contact card, tiebreak option 8 was then defined between the shells with respect to the parameters obtained experimentally for stitched and non-stitched specimens. The current tiebreak formulations require a fixed set of input parameters that include, or can be calculated from, the Mode I and Mode II interlaminar fracture toughness values. In the stitched area the PARAM' was increased according to the experimental data and non-stitched area normal PARAM' was used. This increases $G_{I C}$ energy release rate within the stitched area and replicates the stitched specimen.

\subsection{FEA result and discussion}

Figures 12 and 13, compares the plane morphology between FEA model and experimental crushing process. The comparison shows internal and external petal formation with bundle fracture in FE results. The force-crush distance curve was extracted from FE model and compared with the relevant experimental results (see Figure 14).

Figure 14a, represents GFRP non-stitched experimental and numerical results. The mean crush force is $69 \mathrm{kN}$ for experimental and $68 \mathrm{kN}$ for numerical. Figure 14b, represents CFRP nonstitched and it has a mean crush force of $63 \mathrm{kN}$ and $62 \mathrm{kN}$ for experimental and numerical respectively. GFRP stitched specimen has a mean crush force of $84 \mathrm{kN}$ and $82 \mathrm{kN}$ for experimental and numerical respectively (see Figure 14c). In Figure 14d, CFRP stitched specimen has a mean crush force of $80 \mathrm{kN}$ and $79 \mathrm{kN}$ for experimental and numerical respectively. 
The difference between the mean force and energy absorption of FE model and experimental studies is less than 5\% (see Figure 14). In Figure 15, the energy absorption capability of stitched and non-stitched specimens are shown. In both parts, CFRP and GFRP absorbers, the stitched specimens showed better crashworthy behaviour as the applied energy was absorbed considerably faster over time. This method of modelling is capable of predicting Mode-I crack propagation in the inter wall of the composite tubes which has a major role in energy absorption capability and progressive crushing process (see Figure 16). 

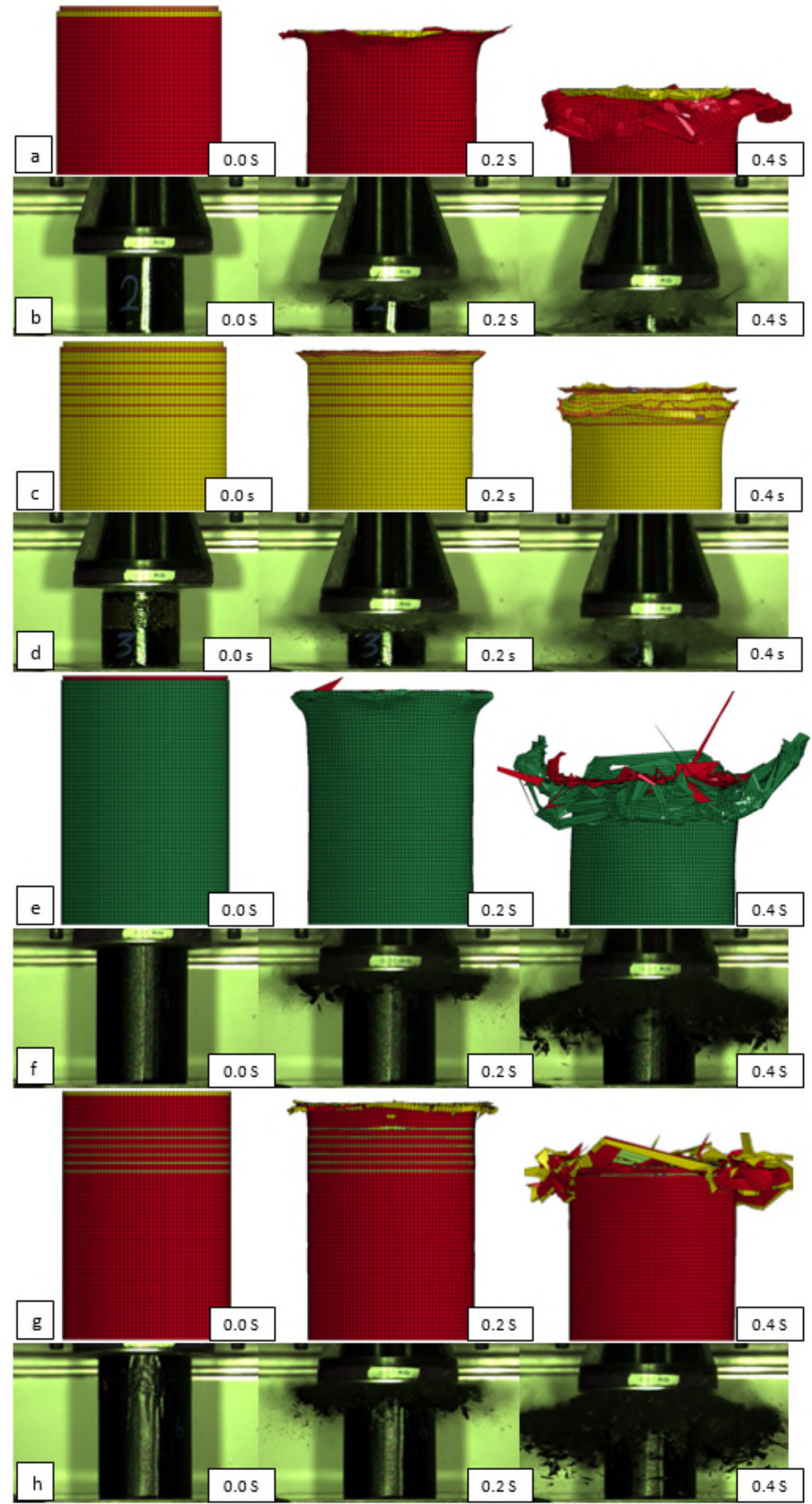

Fig 12.

stages of impact testing and simulations at 0, 0.2 and 0.4 of a second. a) FEA simulation of non-stitched GFRP b) experimental process of non-stitched GFRP c) FEA simulation of multi-stitched GFRP d) experimental process of multi-stitched GFRP, e) FEA of non-stitched CFRP, f) experimental process of non-stitched CFRP, g) FEA of multistitched CFRP and $h$, experimental process of multi-stitched CFRP specimens. 

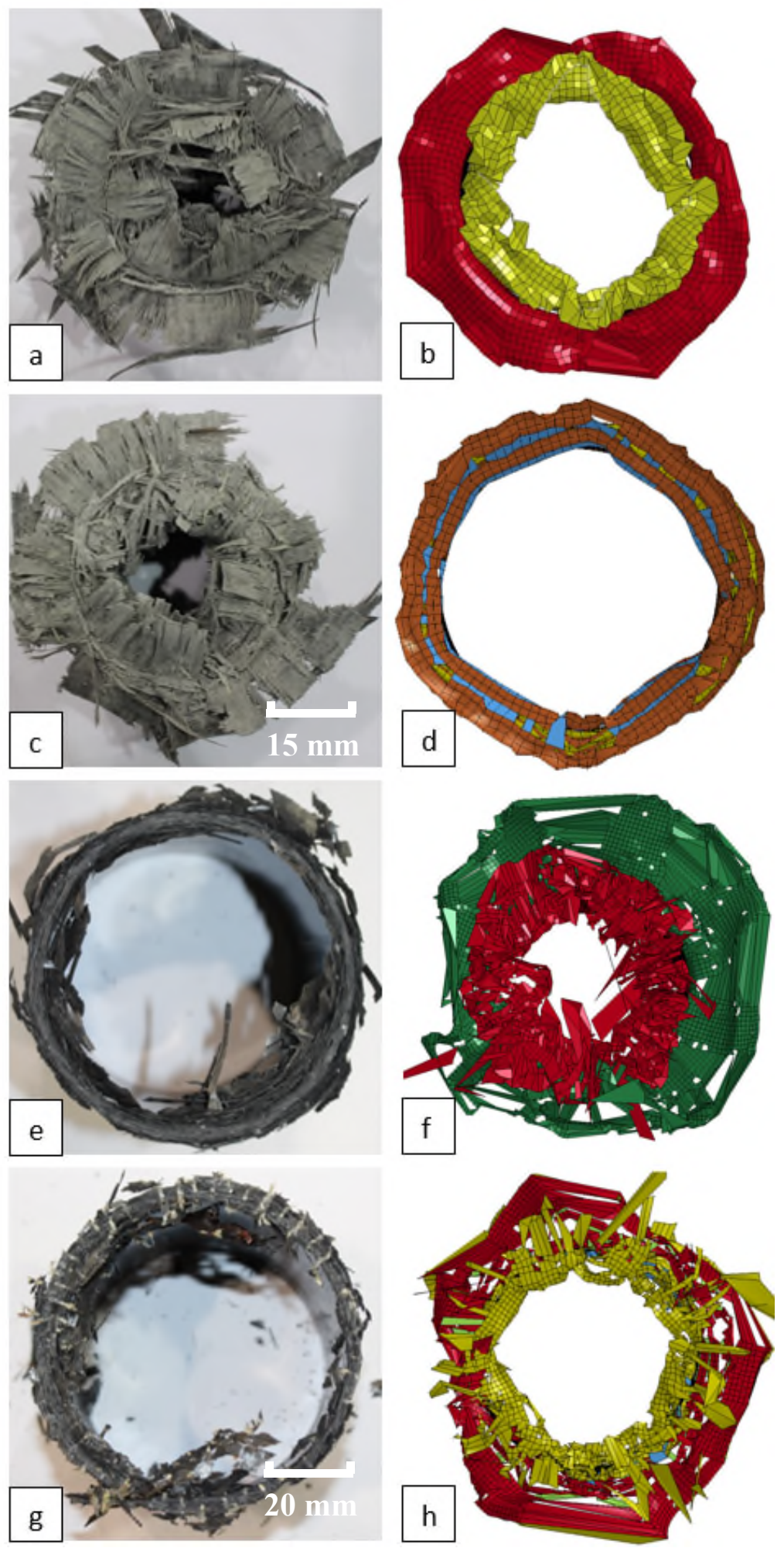

Fig 13. Plane view of the tested GFRP and CFRP under impact load a) non-stitched GFRP experiment b) nonstitched GFRP FEA c) stitched GFRP experiment d) stitched GFRP FEA e) non-stitched CFRP experiment f) nonstitched CFRP FEA g) stitched CFRP experiment h) stitched CFRP FEA. 

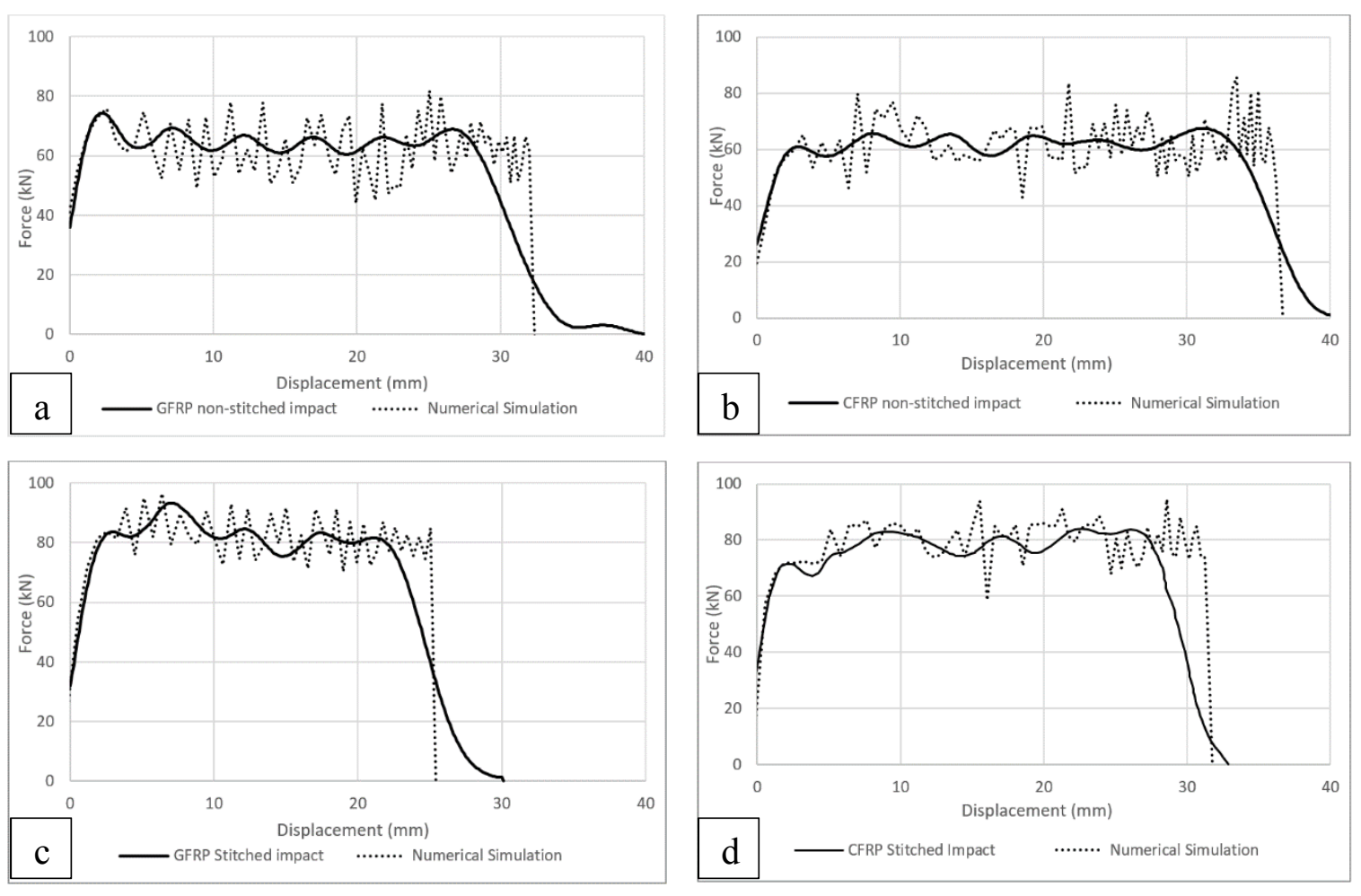

Fig 14. Force-displacement of the tested GFRP and CFRP under impact loading a) stitched and non-stitched GFRP b) stitched and non-stitched CFRP c) GFRP stitched FEA and experiment d) non-stitched CFRP FEA and experiment e) GFRP stitched FEA and experimental f) stitched CFRP FEA and experiment.
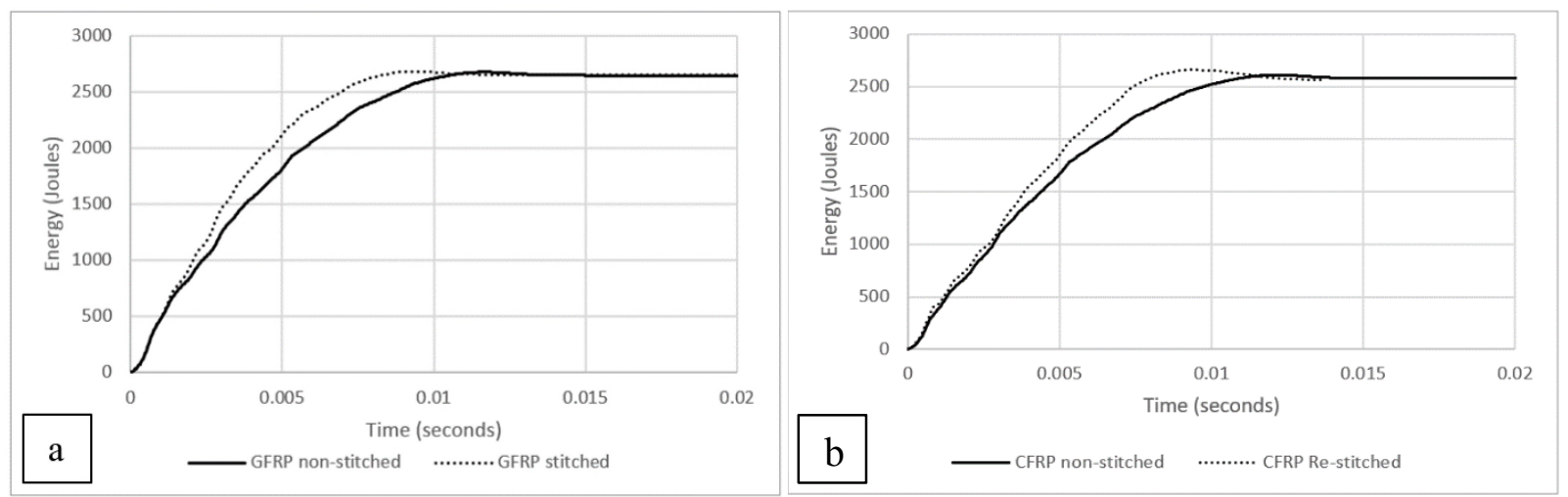

Fig 15. Energy vs time a) GFRP stitched and non-stitched b) CFRP stitched and non-stitched. 


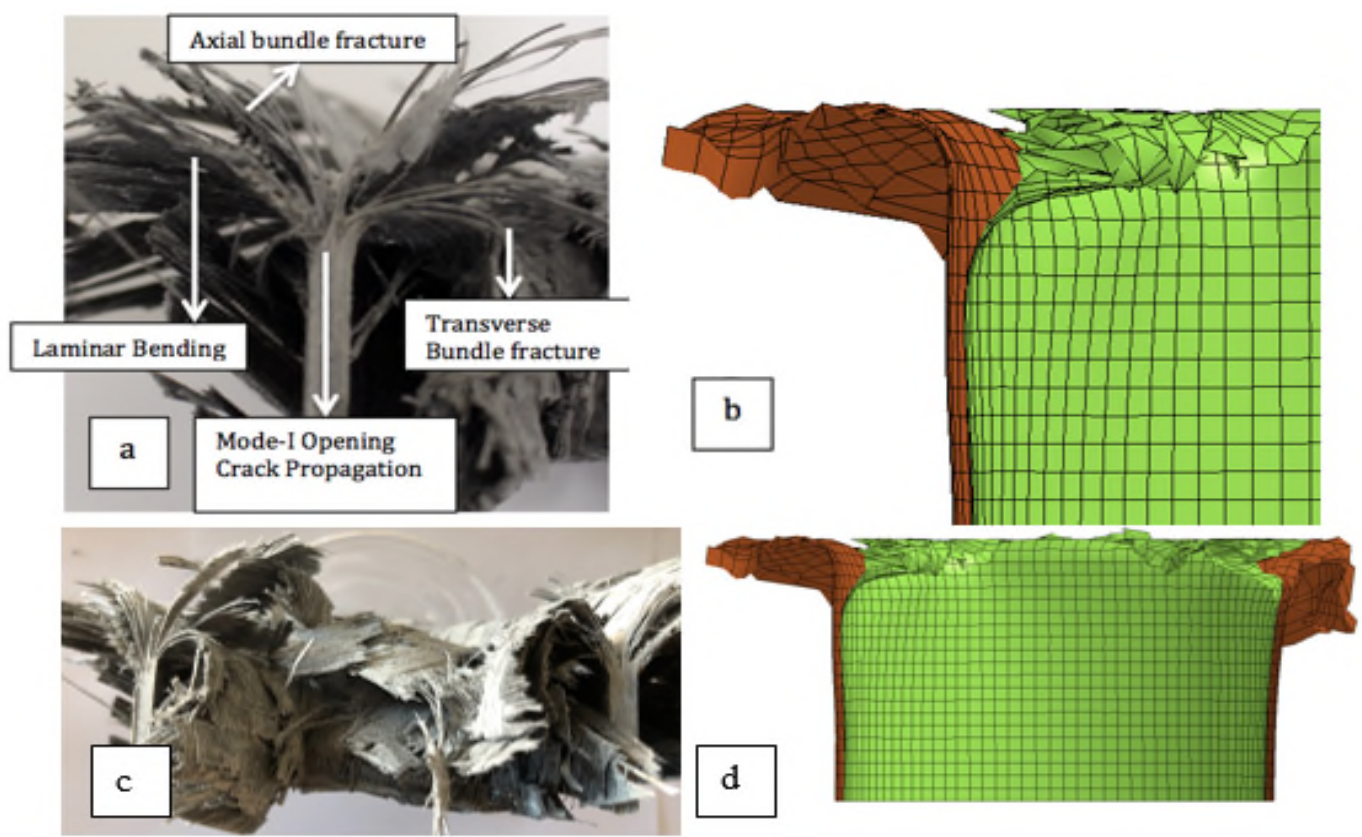

Fig 16. Crack Propagation at central inter-wall a) axial failure mechanism b) axial FEA c) axial experiment d) axial FEA.

\section{Conclusion}

In this study, first, the effect of stitching on the energy absorption capabilities of composite absorbers was studied experimentally. The failure mechanisms were circumferential delamination, axial cracks, laminar bending, and bundle fractures modes. In both types of composite materials, stitched specimens had higher energy absorption capability compared to non-stitched ones. The specific energy absorption of GFRP and CFRP composite tubes are $17 \%$ and $18 \%$ higher than non-stitched sections respectively. This behaviour significantly increases crashworthiness performance of composite absorbers subjected to impact loading and consequently maximises energy absorption capability. Multi-stitching through the thickness has shown significant lightweight potential.

In the second part, the multi-layered finite element model was developed in LS-DYNA software to create a numerical model for further studies in terms of failure analysis in stitched and non-stitched composite crash absorbers. The approach was through Tiebreak option 8 , to model delamination, as this contact card can define Mode-I and Mode-II energy release rates which simulate delamination and debonding. An energy-based approach was used to determine the input parameters for the tiebreak formulations to accurately simulate delamination between 
the plies. A scaling factor was introduced to account for ply interfaces that were not represented by a tiebreak definition. The numerical model is capable to predict the impact behaviour of composite crash absorbers with a reasonable accuracy (2-4\% error compared with experimental results). The present study has established sufficient information on the effect of stitching through the thickness of crushing behaviour subjected to axial impact loading. This enables the control of the force-crush distance curve to behave at a certain standard in regards to crashworthiness and weight saving applications in automotive and aerospace industry, where the increase of specific energy absorption capabilities of the structure is one of the critical considerations.

\section{References}

[1] Esnaola, A. Ulacia, I. Aretxabaleta, L. Aurrekoetxea, J. Gallego, I. Quasi-static crush energy absorption capability of e-glass/polyester and hybrid e-glass basalt/polyester, Compos Structures. 76 (2015), pp. 18-25, ISSN 0261-3069.

[2] Liu, Q. Xing, H. Ju, Y. Ou, Z. Li, Q. Quasi-static axial crushing and transverse bending of double hat shaped CFRP tubes, Composite Structures. 117 (2014), pp. 1-11, ISSN 02638223.

[3] Bisagni, C. Experimental investigation of the collapse modes and energy absorption characteristics of composite tubes. Int J Crash. 14 (2009), pp. 365-78.

[4] Taher, S.T. Mahdi, E. Mokhtar, A.S. Magid, D.L. Ahmadun, F.R. Arora, P.R. A new composite energy absorbing system for aircraft and helicopter. Composite Structures, 75 (2006), pp. 14-23.

[5] Carruthers, J.J. Kettle, A.P. Robinson, A.M. Energy absorption capability and crashworthiness of composite material structures: a review, Appl. Mech. Rev. 51 (1998), pp. 635-649, ISSN 0003-6900.

[6] Zhu, G. Sun, G. Liu, Q. Li, G. Li, Q. On crushing characteristics of different configurations of metal-composites hybrid tubes, Composite Structures. 175 (2017) pp. 5869.

[7] Rabiee, A. and Ghasemnejad, H. Progressive Crushing of Polymer Matrix Composite Tubular Structures: Review. Open Journal of Composite Materials, 7 (2017), pp. 14-48.

[8] Farley, G.L. The Effect of Crushing Speed on the Energy-Absorption Capability of Composite Tubes. Journal of Composite Materials, 25 (1991), pp.13-14.

[9] Mamalis, A.G., Manolakos, D.E. and Viegelahn, G.L. Crashworthy Behaviour of ThinWalled Tubes of Fibreglass Composite Material Subjected to Axial Loading. Journal of Composite Materials, 24 (1990), pp. 72-91. 
[10] Alif N., Carlsson L.A, Boogh L. The effect of weave pattern and crack propagation direction on mode I delamination resistance of woven glass and carbon composite.

Composites Part B, 29 (B) (1998), pp. 603-611.

[11] Korkiakoski, S. Sarlin, E. Suihkonen, R. Saarela, O. Influence of reinforcement positioning on tension-tension fatigue performance of quasi-unidirectional GFRP laminates made of stitched fabrics. Composites Part B, 112 (2017), pp. 38-48.

[12] Dransfield, K. Baillie, C. Mai, YW. Improving the delamination resistance of CFRP by stitching - a review. Compos Sci Technol, 50(3) (1994), pp. 305-17.

[13] Mouritz, AP. Cox, B.N. A mechanistic approach to the properties of stitched laminates. Compos Part A: Appl Sci Manuf, 31 (2000), pp. 1-27.

[14] Cauchi-Savona S. Zhang C. Hogg P. Optimisation of crush energy absorption of noncrimp fabric laminates by through-thickness stitching. Compos A: Appl Sci Manuf, 42 (7) (2011), pp. 712-722.

[15] Solaimurugan, S. and Velmurugan, R. Influence of fibre orientation and stacking sequence on petalling of glass/polyster composite cylindrical shell under axial compression. Int Jnl of Solid and Structures, 44:44 (2007), pp. 6999-7020

[16] Solaimurugan, S. and Velmurugan, R. Progressice crushing of stitched glass/polyester composite cylindrical shells. Compos Sci Technol, 67 (2007), pp. 422-437.

[17] Korkiakoski, S. Sarlin, E. Suikonen, R. Saarela, O. Influence of reinforcement positioning on tension-tension fatigue performance of quasi-unidirectional GFRP laminates made of stitched fabrics, Composite Part B, 112 (2017), pp. 38-48

[18] Ghasemnejad, H. and Hadavinia, H. Off-axis crashworthiness characteristic of woven glass/epoxy composite box structures. J. Reinf Plast Comp, 29(15) (2010), pp. 2306-2330.

[19] Ghafari-Namini, N. and Ghasemnejad, H. Effect of natural stitched composites on the crashworthiness of box structures. Materials \& design, 39 (2012), pp. 484-494.

[20] Rabiee, A. Ghasemnejad, H. Effect of multi stitched locations on high speed crushing of composite tubular structures, Composites Part B: Engineering, 100 (2016), pp. 164-175.

[21] Ghasemnejad, H. Blackman , H.R.K. Hadavinia, H. Sudall, B. Experimental studies on fracture characterisation and energy absorption of GFRP composite box structures. Compos Struct, 88 (2009), pp. 253-261.

[22] Feindler, N. Charakterisierungs- und Simulationsmethodik zum Versagensverhalten energieabsorbierender Faserverbundstrukturen ( $\mathrm{PhD}$ thesis). Munich: Technical University of Munich; 2012. ISBN: 978-3-8439- 1557-1.

[23] Pinho, S.T. Camanho, P.P. De Moura, M.F. Numerical simulation of the crushing process of composite materials. Int J Crashworthiness, 9 (2004), pp. 263-276.

[24] Siromani, D. Awerbuch, J. Tan, T.-M. Finite element modelling of the crushing behaviour of thin-walled CFRP tubes under axial compression. Compos Part-B, 64 (2014), pp. 50-58. 
[25] Johnson, A.F. Modelling fabric reinforced composites under impact loads. Compos Appl Sci Manuf, 32 (2001), pp. 1197-1206.

[26] Joosten, M.W. Dutton, S. Kelly, D. Experimental and numerical investigation of the crushing response of an open section composite energy absorbing element. Compos Struct, 93 (2011), pp. 682-689.

[27] Holzapfel, M. Grundolf, K. Adamski, P. Elsenhans, H. Doll, J. Hambrecht, T. Untersuchungen zur Modellierung von Strukturen aus FKV unter Crashbelastung mit. Hilfe von Mehrschalen modellierungen. In: 7th German LS-DYNA Users Conference, Bamberg, 2008 .

[28] Pinho, S.T. Camanho, P.P. De Moura, M.F. Numerical simulation of the crushing process of composite materials. Int J Crashworthiness, 9 (2004), pp. 263-276.

[29] LNS, Ciou. BG, Falzon. R, Boman. Et al. Finite element modelling of composite structures under crushing load. Compos struct 2015;131:215-28

[30] Rabiee, A. Ghasemnejad, H. Laminate Tailoring of Composite Tubular Structures to Improve Crashworthiness Design at Off-Axis Loading. Open Journal of Composite Material, 8(3) 84-109.

[31] Tan, K.T. Watanabe, N. Iwahori, Y. Stitch fiber comparison for improvement of interlaminar fracture toughness in stitched composites. Reinforced Plastics \& Composites, 30(2) 99-109.

[32] Hallquist, J.O. LS-DYNA Keyword User's Manual, Version 971, Volumes 1 and 2, Livermore Software Technology Corporation, Livermore, California, May 2007. 
2018-11-19

Lightweight design to improve crushing behaviour of multi-stitched composite tubular structures under impact loading

\title{
Rabiee, Ali
}

Elsevier

\begin{abstract}
A. Rabiee, H. Ghasemnejad. (2019) Lightweight design to improve crushing behaviour of multi-stitched composite tubular structures under impact loading. Thin-Walled Structures, Volume 135, February 2019, pp. 109-122
\end{abstract}

https://doi.org/10.1016/j.tws.2018.11.002

Downloaded from Cranfield Library Services E-Repository 